
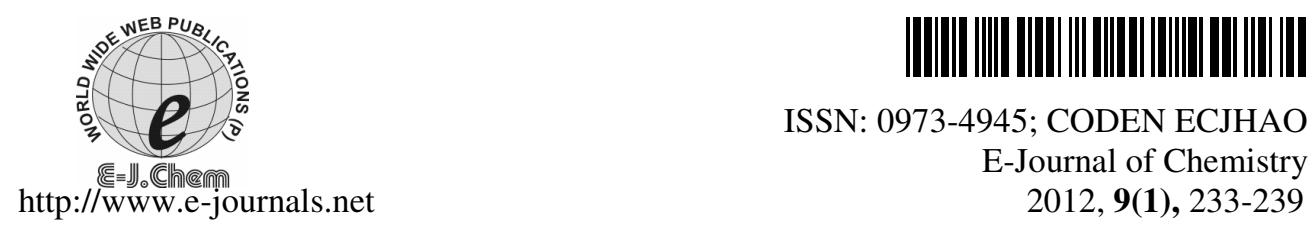

ISSN: 0973-4945; CODEN ECJHAO

E-Journal of Chemistry 2012, 9(1), 233-239

\title{
Control of the Morphology of Molybdenum Dioxide Nanoparticles
}

\author{
R. NAOUEL, F. TOUATI* and N. GHARBI \\ Laboratoire de Chimie de la Matière Condensée \\ Université de Tunis., Institut Préparatoire aux Etudes d'Ingénieur de Tunis \\ 2 rue Jawaher Lel Nehru 1089 Montfleury-Tunis, Tunisia \\ *Institut Nationale de Recherche et d'Analyse Physico-chimique \\ Technopôle Sidi-Thâbet, Tunisia \\ fathi19612004@yahoo.fr
}

Received 27 November 2010; Accepted 22 January 2011

\begin{abstract}
Synthesis of $\mathrm{MoO}_{2}$ nanoparticles with one-dimensional (1D) and spherical morphologies in aqueous solutions, through hydrothermal process was investigated. The materials were studied by x-ray diffraction (XRD), scanning electron microscopy (SEM), transmission electron microscopy (TEM), Infrared spectroscopy (FTIR) and thermal analysis (TG). It was found that the quantity of organic compound influenced the size and shape of the final product. The possible formation mechanism of $\mathrm{MoO}_{2}$ microspheres and nanowires was also discussed. The conductivity of $\mathrm{MoO}_{2}$ nanowires was explained by the presence of two protons types in the material.
\end{abstract}

Keywords: Nanoparticles, $\mathrm{MoO}_{2}$, Nanowires, Electrical properties

\section{Introduction}

It is well-known that the shape and size of materials have great influence on their physical properties. In the past decade, many efforts were devoted to the synthesis of semiconductor nanowires], nanorods ${ }^{2-3}$, nanobelts ${ }^{4}$ and nanoshells ${ }^{5-6}$, due to the importance of understanding the dimensionality confined transport phenomena and fabricating nanodevices and nanosensors ${ }^{7-8}$.

One dimensional systems constitute a new class of advanced materials. They have attracted a great deal of research interest because of their potential applications ranging from molecular electronics, thermoelectric devices to chemical sensors ${ }^{9-13}$. Many ways allow to the control, the direct growth and the assembly of nanoscale particles, such as microemulsion $^{14}$ and chemical vapour deposition ${ }^{15}$. Among these methods, polymer encapsulation could be an appropriate way to control the growth and the assembly of inorganic nanoparticles. 
Molybdenum dioxide is a promising material for applications in catalysts, sensors, electro-chromic and recording devices ${ }^{16-18}$. The 1-D nanostructures of $\mathrm{MoO}_{2}$ maybe prepared by carbon nanotubes templated growth ${ }^{19}$ or, as reported recently, by thermal evaporation ${ }^{20}$. The $\mathrm{MoO}_{2}$ nanorods prepared by thermal evaporation show the possibility of applications in the emission devices field ${ }^{21}$.

In this work, we expose how, at relatively low temperature, the growth and the assembly of molybdenum dioxide nanowires can be used as a simple method to direct polymer coating process and consequently the resulting core shell morphology.

\section{Experimental}

X-ray diffraction patterns were recorded for all samples using Panalytical "X'Pert Pro" diffractometer, at a scanning rate of $2 \% \mathrm{~min}$ and a step of $0.02^{\circ}$ and using $\mathrm{Cu} \mathrm{K}_{\alpha}$ radiation $\left(\lambda=1.54056^{\circ}\right)$. The texture of the prepared samples was examined using a scanning electron microscope (SEM) quanta 200 and transmission electron microscope (TEM) JEOL 100 CX II that operated at $200 \mathrm{KV}$. One droplet of the powder dispersed in $\mathrm{CH}_{3} \mathrm{CH}_{2} \mathrm{OH}$ was deposited onto a carbon-coated copper grid and left to dry in air. Thermal analysis (DTA-TG) were performed using Setaram Setsys 1750 at a heating rate of $10{ }^{\circ} \mathrm{C} \cdot \mathrm{min}^{-1}$ from 25 to $1000{ }^{\circ} \mathrm{C}$ in a flow of argon and under air atmosphere. Fourier transform infrared spectra (FTIR) were recorded with a Nicolet 380. Spectrometer, impedance measurements were carried out in air on pressed pellets, as a function of frequency (5-13 Mhz) using an HP4192 impedance meter.

\section{Sample preparation}

The synthesis of molybdenum dioxide was carried out through hydrothermal process. Molybdenum trioxide $\mathrm{MoO}_{3}$ and paraphenylendiamine $\left(\mathrm{NH}_{2} \mathrm{C}_{6} \mathrm{H}_{4} \mathrm{NH}_{2}\right)$ was introduced in $5 \mathrm{~mL}$ of distilled water with different molar ratio $\left(\mathrm{k}=\mathrm{n}_{\text {inorg }} / \mathrm{n}_{\text {org }}\right)$. This mixture was treated in Parr bomb at $220{ }^{\circ} \mathrm{C}$ with the variation of $\mathrm{k}$. The reaction time was fixed at $72 \mathrm{~h}$ and cooling time of this system was $24 \mathrm{~h}$. The $\mathrm{pH}$ of the reaction mixture remains close to 7 . The obtained black powder was washed with acetone to remove residues of unreacted paraphenylendiamine and then dried at $80{ }^{\circ} \mathrm{C}$ for $2 \mathrm{~h}$.

\section{Results and Discussion}

\section{$X$-ray diffraction}

Figure 1 illustrates the XRD patterns of the obtained product as a function of k. The sharp diffraction peaks reveal that the products are perfectly crystallized. All resulting patterns were in accordance with monoclinic $\mathrm{MoO}_{2}\left(\mathrm{P} 2_{1}\right)$ and its cell parameters were refined with wincell program. The resulting values were: $\mathrm{a}=5.5024 \AA \mathrm{A}, \mathrm{b}=4.8685 \AA, \mathrm{c}=5.4859 \AA$ and $\beta=118.421^{\circ}$ and in accordance with JCPDS65-1273 data card number. No peaks of any other phases or impurities were observed from the XRD patterns, indicating the high purity of monoclinic $\mathrm{MoO}_{2}$.

\section{Infrared spectroscopy}

Figure 2 shows that the infrared spectra of the two obtained samples are similar. Indeed, the narrow line at $890 \mathrm{~cm}^{-1}$ is assigned to $\left(v_{\mathrm{Mo}=\mathrm{O}}\right)$, while the peak at $674 \mathrm{~cm}^{-1}$ is associated to the ( $v_{\text {Mo-O-Mo }}$ ) vibration. In addition, the broad band at $3427 \mathrm{~cm}^{-1}$ is attributed to the $\mathrm{N}-\mathrm{H}$ stretching. The band at $1160 \mathrm{~cm}^{-1}$ is characteristic of the $\mathrm{N}=\mathrm{Q}=\mathrm{N}$ units ( $\mathrm{Q}$ corresponds to the quinoid groupment) and the vibration at $1297 \mathrm{~cm}^{-1}$ is in agreement with the $\mathrm{C}-\mathrm{N}$ stretching 
vibrations. The band at $820 \mathrm{~cm}^{-1}$ corresponds to the $\mathrm{C}-\mathrm{H}$ bonding mode and the band at $1619 \mathrm{~cm}^{-1}$ may be attributed to the $\mathrm{C}=\mathrm{C}$ bond. This result indicates the presence of the paradisubstituted aromatic compound.

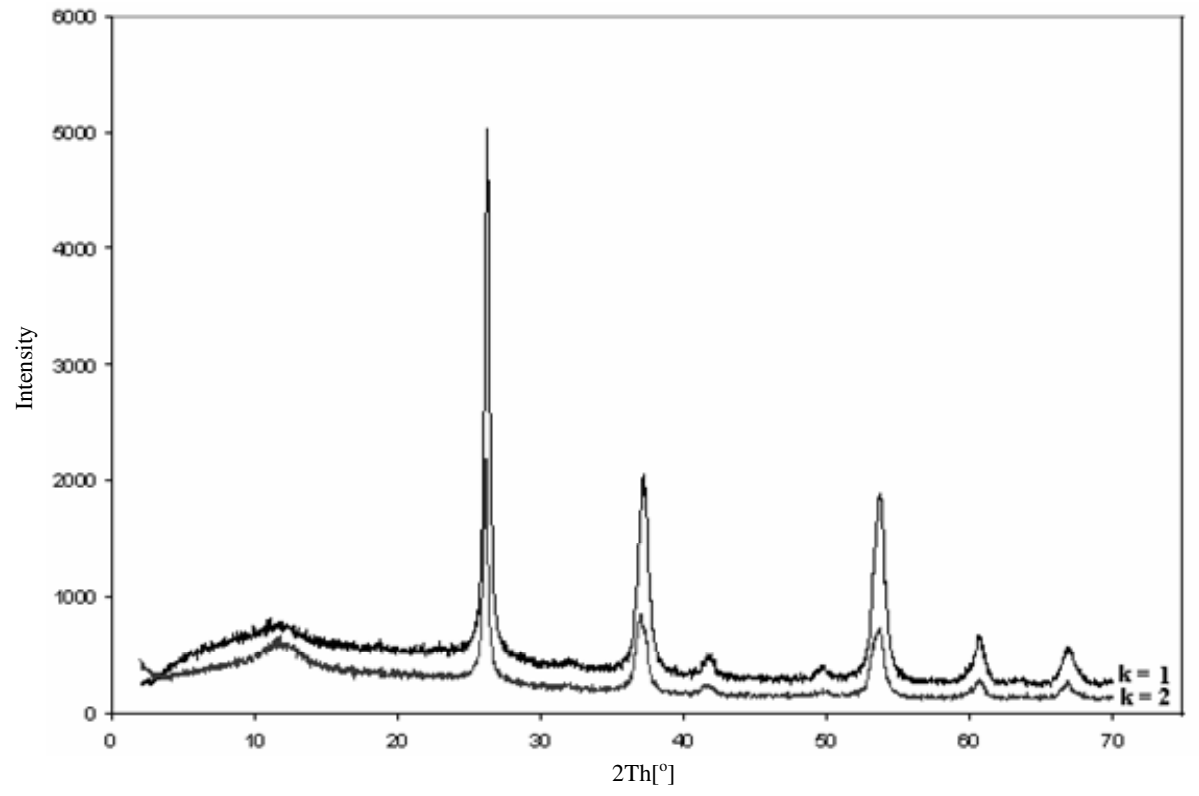

Figure 1. XRD patterns of the products formed with different value of $k$

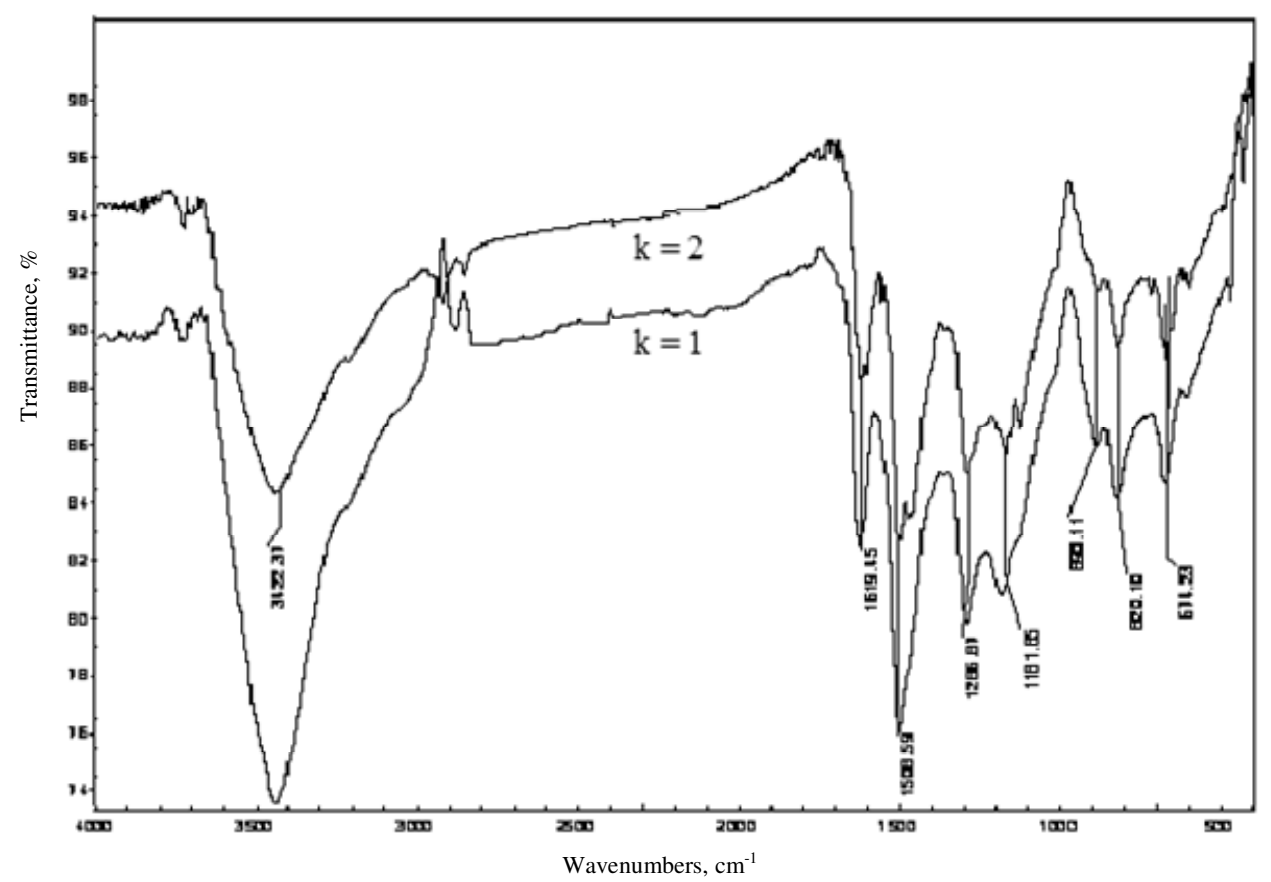

Figure 2. IR spectra of the formed product with different value of $\mathrm{k}$ 


\section{Scanning and transmission electronic microscopy}

The SEM micrographs of the two samples with the molar ratio 1 and 2 were represented by Figure 3. It is noticed that the obtained product for $\mathrm{k}=1$ (Figure 3a) is mainly constituted by spherical particles with micrometer dimensions $(1-3 \mu \mathrm{m})$. The TEM image (Figure 4a) confirms the presence of nanoparticles inside the microspheres structure. On the basis of the SEM and TEM images of the sample obtained with $k=2$ (Figure 3b, Figure $4 b$ ), the nanowires particles were found to be mixed with a small quantity of microspheres. This result indicates that the decrease of the amount of organic reactant leads to the apparition of $\mathrm{MoO}_{2}$ nanowires.
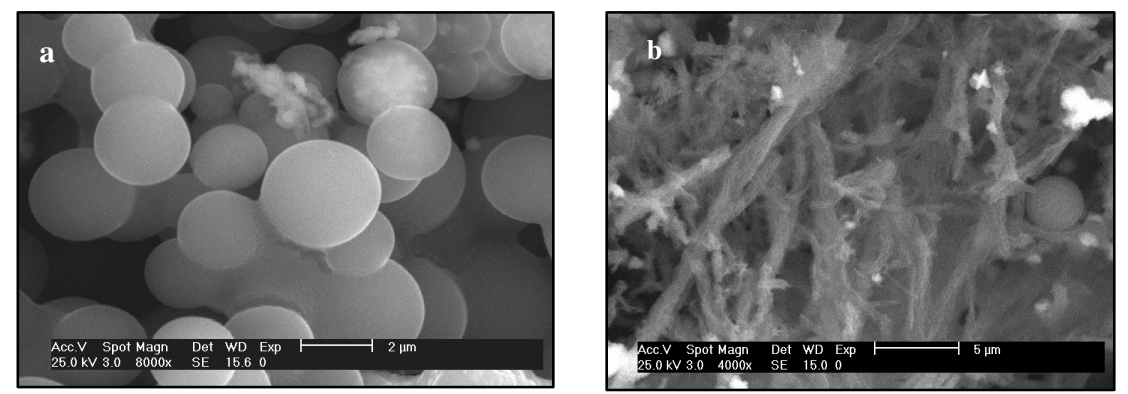

Figure 3. SEM with molar ratio (a) $k=1$ and (b) $k=2$
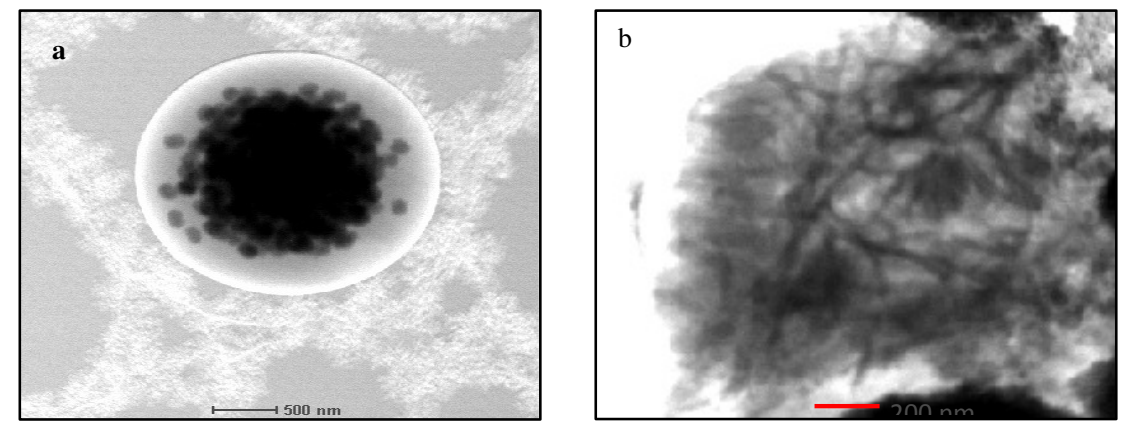

Figure 4. TEM micrographs of the material with molar ratio (a) $\mathrm{k}=1$ and (b) $\mathrm{k}=2$.

\section{Thermal analysis}

The thermal study of the two samples was performed under air atmosphere. Figure 5 shows the thermogravimetric plots of the two samples. These thermograms exhibit a similar thermal comportment and reveal a total mass loss $[(\mathrm{k}=1,25.5 \%)(\mathrm{k}=2,20.5 \%)]$, which can be divided into two steps. The first step $\left(30-120{ }^{\circ} \mathrm{C}\right.$, mass loss: $\left.2 \%\right)$ is attributed to the departure of physisorbed water. In the second step $\left(380-550{ }^{\circ} \mathrm{C}\right)$, the mass loss is different for the two samples. These phenomena correspond to the combustion of organic coating materials and the oxidation of molybdenum dioxide. This dissimilarity can be attributed to the change of the morphology.

\section{Electrical properties of the as-prepared $\mathrm{MoO}_{2}$ nanowires}

The temperature dependence of the conductivity obtained from impedance analyses is presented in Figure 6 with a $\log (\sigma \mathrm{T})$ versus $1000 / \mathrm{T}$ plot. It is interesting to note that the obtained arrhenius plot for the synthesized $\mathrm{MoO}_{2}$ nanowires consists in two distinct straight 
lines with common value at $364 \mathrm{~K}$. The first one, below $364 \mathrm{~K}$, corresponds to the activation energy $E_{1}$ that is equal to $0.193 \mathrm{eV}$, while the second one $\mathrm{E}_{2}$ is equal to $0.053 \mathrm{eV}$. The break that occurred in graphic curves coincides with the loss of water structure observed in the thermogram. This result suggests that the conductivity may be due to the presence of two protons types in the material.

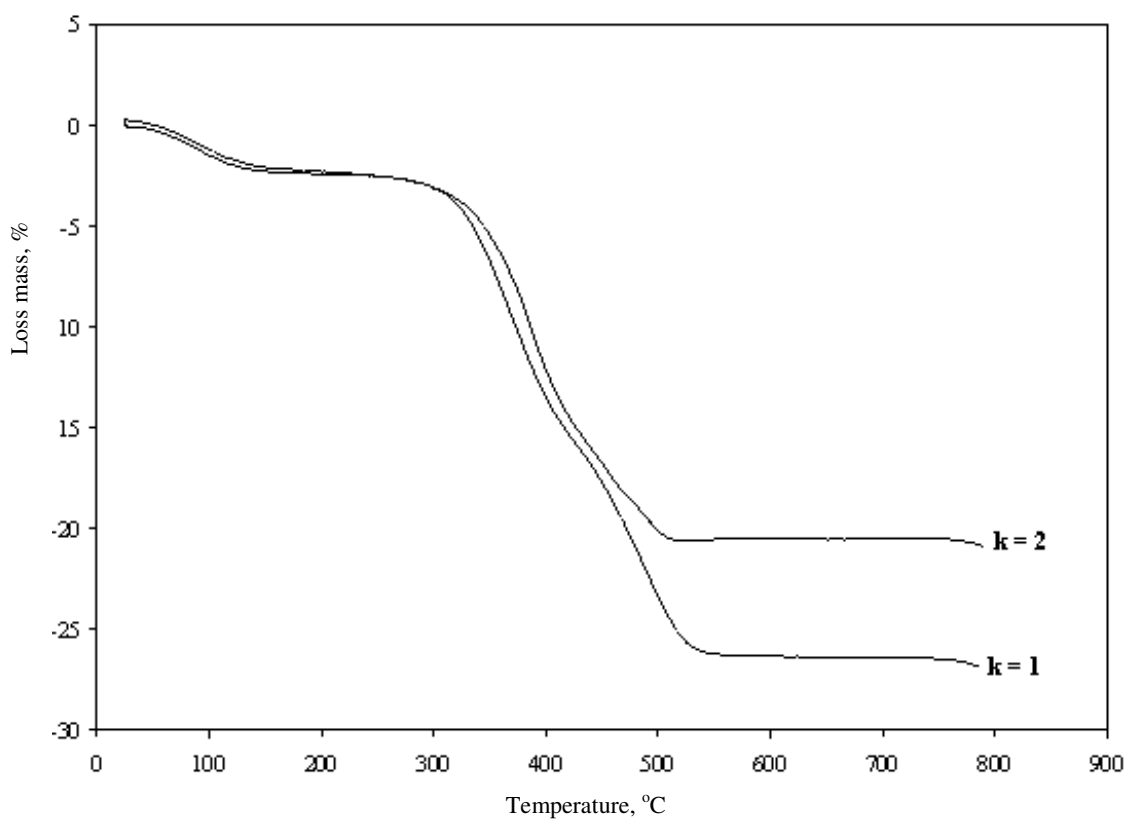

Figure 5. TG curves of the synthesized sample under air atmosphere with different value of $\mathrm{k}$

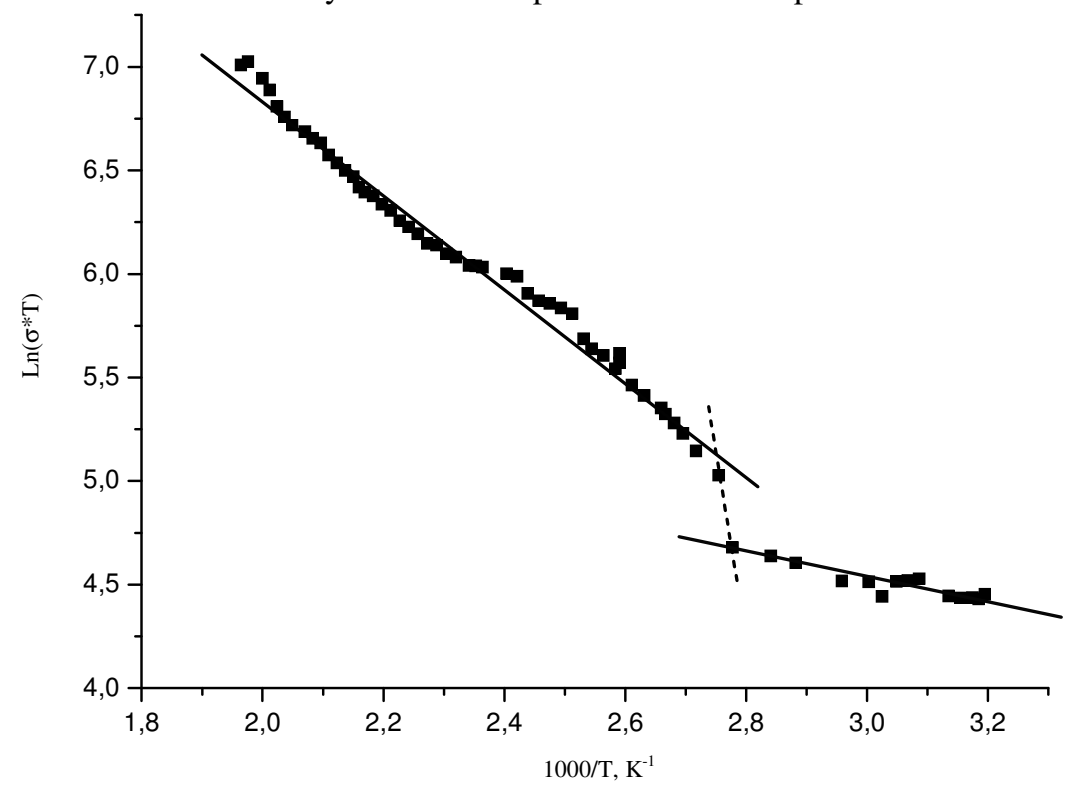

Figure 6. Arrhenius plot $\ln (\sigma \mathrm{T})$ versus $1000 / \mathrm{T}$ of the synthesized nanofibers 
It seems that the conduction mode with the high activation energy is attributed to the proton provided by surface water but the conduction mode with low activation energy is probably related with the existence of hydrogen atom linked to NH-groups in diphenylamine and to the inserted water molecules in the $\mathrm{MoO}_{2}$ lattice.

\section{Possible formation mechanism of $\mathrm{MoO}_{2}$}

The formation process for $\mathrm{MoO}_{2}$ sphere may be supposed as follows. $\mathrm{MoO}_{2}$ colloidal particles were produced in the solution by the redox reaction between $\mathrm{Mo}_{2} \mathrm{O}_{7}{ }^{2-}$ and $\mathrm{NH}_{2} \mathrm{C}_{6} \mathrm{H}_{4} \mathrm{NH}_{2}$. These chemical reactions were represented by the following equations:

$$
\begin{gathered}
2 \mathrm{MoO}_{3}+\mathrm{H}_{2} \mathrm{O} \longrightarrow \mathrm{Mo}_{2} \mathrm{O}_{7}^{2-}+2 \mathrm{H}^{+}(\mathrm{pH}=6) \\
\mathrm{Mo}_{2} \mathrm{O}_{7}^{2-}+2 \mathrm{H}^{+}+2 \mathrm{NH}_{2} \mathrm{C}_{6} \mathrm{H}_{4} \mathrm{NH}_{2} \longrightarrow 2 \mathrm{MoO}_{2}+3 \mathrm{H}_{2} \mathrm{O}+\hat{\mathrm{HN}}=\square=\mathrm{NH}
\end{gathered}
$$

In the second step, the resulting quinonediimine reacts with the paraphenylene diamine leading to the formation of diphenylamine. This stage initiates the polymerization as detailed in Scheme 1. These obtained organic polymers play an important role in the controlling morphologies. Indeed, if the molar quantity of the organic compound is inferior to the one of inorganic compound $(\mathrm{k}=2)$, we obtain a nanowire morphology. However, for equal molars quantities $(\mathrm{k}=1)$, the morphology of the product transforms to microspheres. In the presence of organic polymers and $\mathrm{MoO}_{2}$ colloidal particles, $\mathrm{MO}_{2}$ nanoparticles formed under hydrothermal conditions nucleate, grow and aggregate along the preferentially c-axis direction of the monoclinic $\mathrm{MoO}_{2}$, resulting in the formation of nanowires. In the presence of an excess of organic molecules the polymerization continues, $\mathrm{MO}_{2}$.

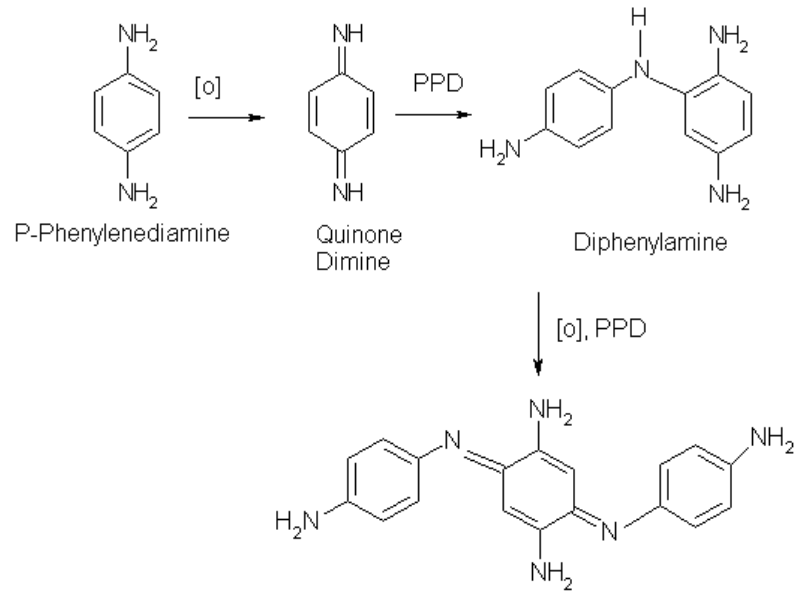

Scheme 1. Formation process of the polymer

Nanoparticles aggregate and are successfully encapsulated into the polymer organic shell. The composite grew in size and their shapes become spherical and smooth.

\section{Conclusion}

Core shell microspheres and nanowires have been synthesized by hydrothermal process. It seems that the molar ratio $\mathrm{k}=\mathrm{n}_{\text {inorg }} / \mathrm{n}_{\text {org }}$ influences the morphology of the obtained materials. The coating process is closely linked with the inorganic self assembly. A possible reaction scheme and formation process mechanism was also proposed. The resulting nanofiber displays an attractive electrical transport properties assured by water protons. 


\section{Acknowledgment}

We would like to thank Prof. Mohamed Ben Salem, Faculté des Sciences de Bizerte, for TEM images and Prof. Hichem Hamzaoui, Centre Nationale des Matériaux, Technopôle Borj-Cedria, for Impedance measurements.

\section{References}

1. Song X.C, Zheng Y.F, Yang E and Wang Y, Mater Lett., 2007, 61, 3904.

2. Li, Z., Luan Y, Mu T and Chen G, Chem Commun., 2009, 1258.

3. Li Z, Jia Z and Mu T, Curr Opin Solid State Mater Sci., 2009, 12, 1.

4. Song X.C, Zhao Y and Zheng Y.F, Mater Lett., 2006, 60, 3405.

5. Yu J.G, Yu J.C, Ho WH, Wu L and Wang X.C, J Am Chem Soc., 2004, 126, 3422.

6. Xia Y and Yang P, Adv Mater 2003, 15, 351.

7. Liu Zhongxin, Song Hongwei, Yu Lixin, Yang Linmei and Pan Guohui, Science in China Ser B Chem., 2005, 48(5), 431.

8. Suchita Kalele S W, Gosavi J Urban and Kulkarni S K, Curr Sci., 2006, 91(8), 1038.

9. Zhang Y, Li L, Li G H and Zhang L D, Physical Review B, 2006, 73, 113-403.

10. He J H, Chang S Lao, Lih J Chen, Dragomir Davidovic, Zhong L Wang, J Am Chem Soc., 2005, 127, 16376-16377.

11. Pu Xian Gao and Zhong L, Wanga, J Appl Phy., 2005, 97, 1-7.

12. Wang Z L, Kong X Y, Ding Y, Gao P, William L, Hugues. Rusen Yang and Yue Zhang, Adv Funct Mater., 2004, 10, 14.

13. Yong Huang, Ke Yu and Ziqiang Zhu, Current Appl Phy., 2007, 7, 702-706.

14. Jianling Zhang, Buxing Han, Juncheng Liu, Xiaogang Zhang, Guanying Yang and Huaizhou Zhao, J Supercritical Fluids, 2004, 30, 89.

15. Dunwei Wang and Hongjie Dai, Angew Chem Int., 2002, 41(24), 4783-4786.

16. Katrib D and Mey G Maire, Catal Today, 2001, 65, 179-183.

17. Yongguang Liang, Shuijin Yang, Zonghui Yi, Xuefeng Lei, Jutang Sun and Yunhong Zhou, Materi Sci Eng B, 2005, 121, 152-155.

18. Satishkumar B C, Govindaraj A, Nash M and Rao C N R, J Mater Chem., 2000, 10, 2115-2119.

19. Zhou J, Xu N S, Deng S Z, Chen J, She J C and Wang Z L, Adv Mater., 2003, 15, 1835-1840.

20. Hong S Y, Popovitz-Biro R, Prior Y and Tenne R, J Am Chem Soc., 2003, 125, 10470.

21. Brunsteiner M, Jones A G, Pratola F, Price S L and SimonsS J R, Cryst Growth, 2005, 5(1), 3-16. 


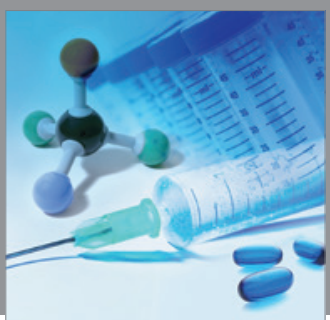

International Journal of

Medicinal Chemistry

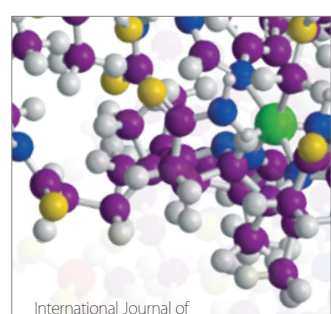

Carbohydrate Chemistry

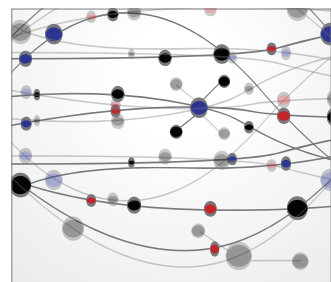

The Scientific World Journal
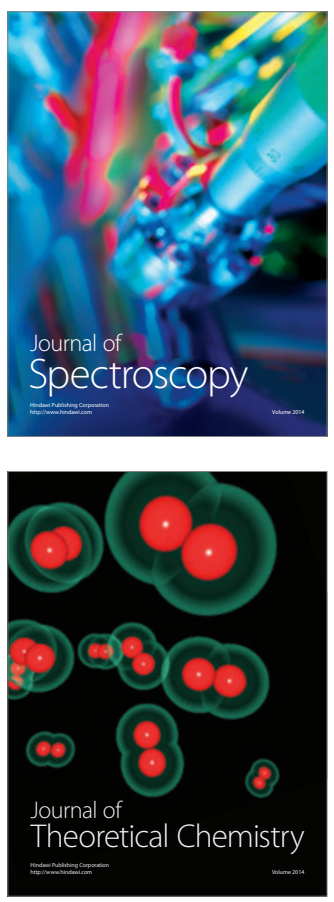
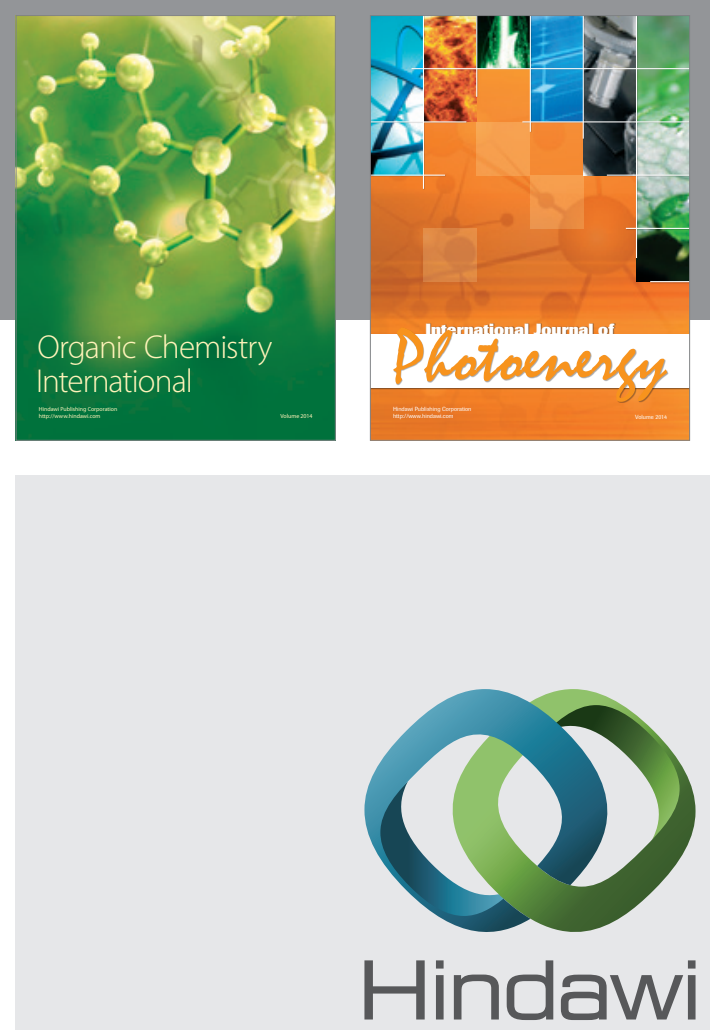

Submit your manuscripts at

http://www.hindawi.com
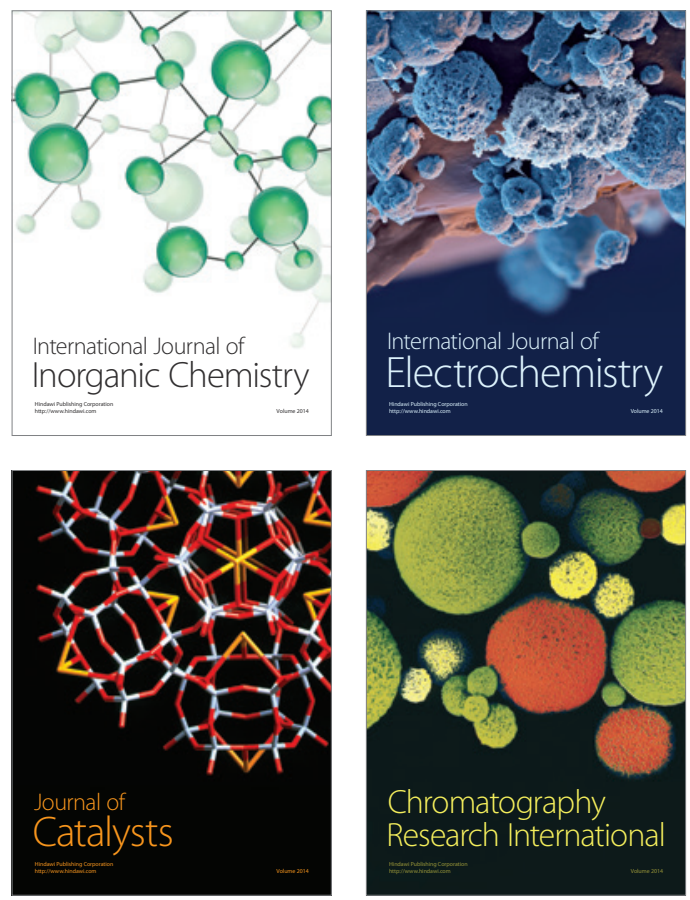
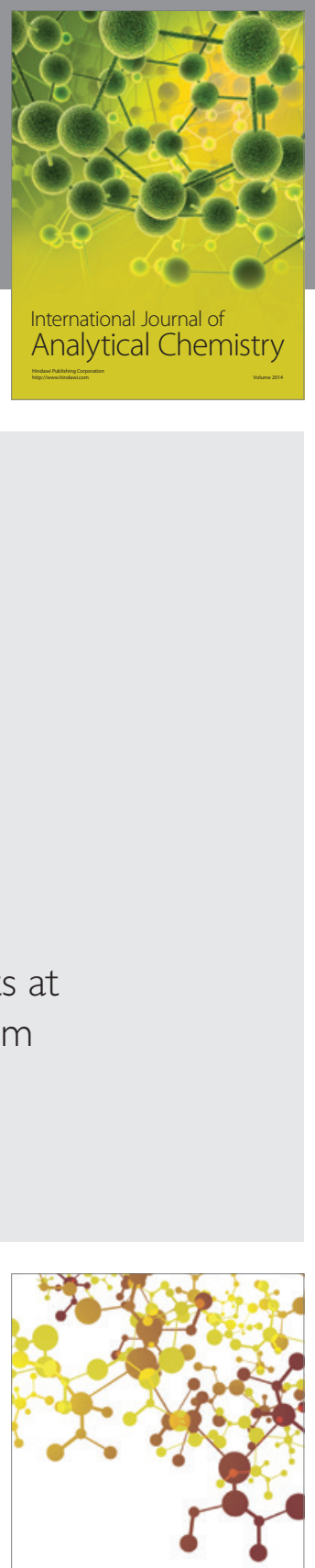

Journal of

Applied Chemistry
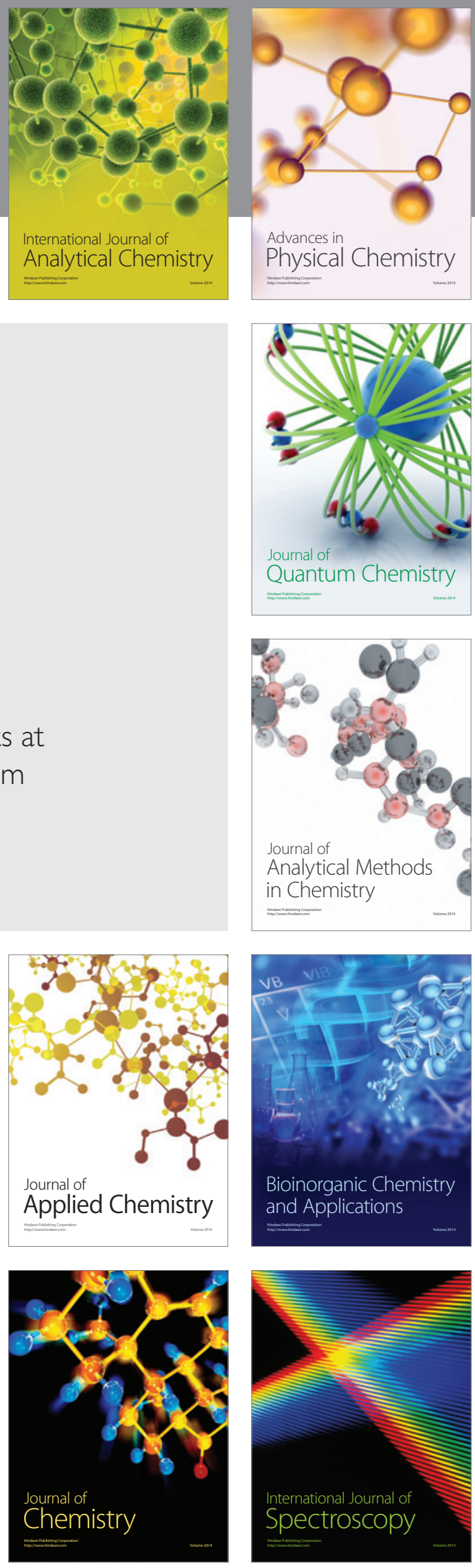